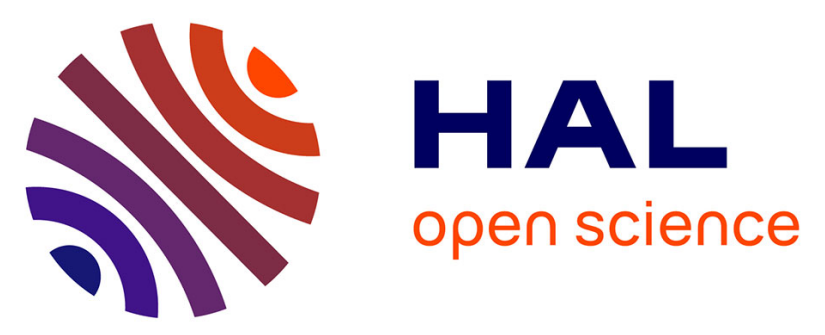

\title{
Poststroke dementia predicting survival in longterm follow-up: influence of prestroke cognitive decline and previous stroke
}

Susanna Melkas, Niku Kj Oksala, Hanna Jokinen, Tarja Pohjasvaara, Risto Vataja, Anni Oksala, Markku Kaste, Pekka J Karhunen, Timo Erkinjuntti

\section{To cite this version:}

Susanna Melkas, Niku Kj Oksala, Hanna Jokinen, Tarja Pohjasvaara, Risto Vataja, et al.. Poststroke dementia predicting survival in longterm follow-up: influence of prestroke cognitive decline and previous stroke. Journal of Neurology, Neurosurgery and Psychiatry, 2009, 80 (8), pp.865. 10.1136/jnnp.2008.166603 . hal-00552738

\section{HAL Id: hal-00552738 https://hal.science/hal-00552738}

Submitted on 6 Jan 2011

HAL is a multi-disciplinary open access archive for the deposit and dissemination of scientific research documents, whether they are published or not. The documents may come from teaching and research institutions in France or abroad, or from public or private research centers.
L'archive ouverte pluridisciplinaire HAL, est destinée au dépôt et à la diffusion de documents scientifiques de niveau recherche, publiés ou non, émanant des établissements d'enseignement et de recherche français ou étrangers, des laboratoires publics ou privés. 


\section{Poststroke dementia predicting survival in longterm follow-up: influence of prestroke cognitive decline and previous stroke}

Susanna Melkas, Niku KJ Oksala, H Jokinen, T Pohjasvaara, R Vataja, A Oksala, M Kaste, PJ Karhunen, T Erkinjuntti

Department of Neurology, Helsinki University Central Hospital, POB 300, 00029 HUS,

Finland Susanna Melkas MD; Division of Vascular Surgery, Department of Surgery, Tampere University Hospital and School of Medicine, Forensic Medicine, University of Tampere and the Laboratory Centre Research Unit, Tampere University Hospital, Finland Niku KJ Oksala MD PhD; Department of Neurology, Helsinki University Central Hospital and Department of Psychology, University of Helsinki, Finland H Jokinen PhD; Department of Neurology, Helsinki University Central Hospital, Finland T Pohjasvaara MD PhD; Department of Neurology, Helsinki University Central Hospital and Department of Psychiatry, University of Helsinki, Finland R Vataja MD PhD; School of Medicine, Forensic Medicine, University of Tampere and the Laboratory Centre Research Unit, Tampere University Hospital, Finland A Oksala MD; Department of Neurology, Helsinki University Central Hospital, Finland M Kaste MD PhD; School of Medicine, Forensic Medicine, University of Tampere and the Laboratory Centre Research Unit, Tampere University Hospital, Finland PJ Karhunen MD PhD;

Department of Neurology, Helsinki University Central Hospital, Finland T Erkinjuntti MD PhD.

Word count (paper): 2728 Word count (abstract): 252 Tables: 5 Figures: 3

Disclosure: The authors report no conflicts of interest.

Statistical analysis: S. Melkas performed the statistical analysis.

Search terms: cerebrovascular diseases; stroke; dementia; mortality

Correspondence to: Susanna Melkas susanna.melkas@hus.fi 


\section{Abstract}

Background: The aim of this study was to investigate the influence of poststroke dementia on longterm survival after acute stroke, focusing also on the possible influence of prestroke cognitive decline and previous stroke. Methods: A total of 451 consecutive acute ischaemic stroke patients admitted to hospital were included in the study and followed up to 12 years. Dementia was diagnosed three months after stroke in 115 patients (25.5\%). Findings: In Kaplan-Meier analysis, poststroke dementia predicted poor longterm survival (5.1 vs 8.8 years, $p<0.001)$. Prestroke cognitive decline had a negative influence on survival of patients with poststroke dementia (3.8 vs 5.8 years, $p<0.001$ ). Previous stroke did not have an influence on survival of these patients $(p=0.676)$. In stepwise Cox regression proportional hazards analysis adjusted with significant covariates, poststroke dementia (HR 1.53, $p=0.003$ ), advanced age (HR 1.07, $p<0.001$ ), severity of stroke (poor Rankin score, HR 1.91, $\mathrm{p}<0.001)$, smoking (HR 1.35, $\mathrm{p}=0.035)$, cardiac failure (HR 1.61, $\mathrm{p}=0.003)$ and atrial fibrillation (HR 1.89, $p=0.035$ ) remained as independent predictors of poor longterm survival. Poststroke dementia (HR 2.33, $\mathrm{p}<0.001)$, advanced age (HR 1.07, $\mathrm{p}<0.001)$ and poor Rankin score (HR 2.15, $p=0.001$ ) were associated with death from brain associated causes including infarction, haemorrhage and dementia. Interpretation: Our large well defined poststroke cohort with longterm follow up indicates that in patients with acute stroke, dementia is a significant predictor of poor longterm survival and death from brain associated causes. Prestroke cognitive decline seems to have an additional negative influence on survival, but previous stroke does not seem to influence survival. 


\section{Introduction}

Lifetime risk for developing stroke, dementia or both is one in three in subjects at 65 years and older. ${ }^{1}$ Stroke is associated with over $50 \%$ risk of death during 5 years and with over $70 \%$ risk of death during 10 years poststroke. ${ }^{2,3}$ The median survival time of patients with dementia is also shorter compared to normal population, ranging between three to nine years depending on the study design. ${ }^{4}$

In community based studies the prevalence of poststroke dementia in stroke survivors is about $30 \%$, and in hospital based studies the prevalence ranges from 5.9 to $32 \%$ depending on the mean age of the study population, delay between stroke and cognitive assessment and criteria for dementia used. ${ }^{5}$ Incidence studies indicate that the risk of poststroke dementia is highest within 6-12 months after stroke and remains doubled even in later, compared to normal population. ${ }^{5}$

Poststroke dementia is an important category in the vascular cognitive impairment. ${ }^{6,7}$ In addition to vascular burden, poststroke dementia relates also to the degenerative burden of the brain. ${ }^{8}$ The importance of vascular factors as cause of Alzheimer disease is still under discussion. ${ }^{9}$ At least stroke seems to be able to initiate a vascular exacerbation that increases the likelihood of clinical dementia diagnosis in a patient with subclinical Alzheimer disease. ${ }^{10}$ Especially in the elderly incident ischaemic cerebrovascular disease relates to clinical expression of dementia associated with Alzheimer disease pathology. ${ }^{8,11}$

Previously, two studies have investigated the influence of poststroke dementia on longterm survival. ${ }^{12,13}$ Both studies indicate that poststroke dementia is an independent predictor of 
survival after adjustment for other predictors of stroke mortality. Short term survival up to three years has been studied in another two studies, ${ }^{14,15}$ showing both prestroke dementia and new onset poststroke dementia as independent predictors of survival. Populations in all these studies have included both patients with first ever stroke and those with previous stroke, but possible differences in survival between these two groups were not analysed.

Based on a well defined poststroke cohort with an up to 12 years follow up we investigated the influence of poststroke dementia and related factors on survival after acute stroke. 


\section{Methods}

\section{Patients}

The Helsinki Stroke Aging Memory (SAM) cohort comprised a consecutive series of all Finnish (Caucasian) patients with suspected stroke admitted to Helsinki University Central Hospital ( $n=1622$ ) between 1 December 1993 and 30 March 1995, as described in detail

previously. ${ }^{16,17}$ Patients aged 55-85 years living in Helsinki were included. Patients without ischaemic stroke $(n=175)$, presenting with intracerebral $(n=229)$ or subarachnoid haemorrhage $(n=69)$ were excluded. A total of 642 patients fulfilled the inclusion criteria and were invited to a follow-up visit three months later. Of these, 71 died $(11.1 \%)$ before the three month follow-up, 82 refused (12.8\%) and 3 were lost $(0.5 \%)$ due to undefined causes. Finally, $486(85.1 \%)$ of the living patients were included in the final SAM cohort. ${ }^{18}$ Of these, $451(92.8 \%)$ were clinically testable with regard to dementia diagnosis. ${ }^{16}$ The study population included no patients with a restroke between the index stroke and the threemonth evaluation. Patient flow and reasons for nonenrollment are shown in the Table1.

The study was approved by the Ethics committee of the Department of Clinical Neurosciences, Helsinki University Central Hospital, Finland. The study was explained to the patients, and informed consent was obtained.

\section{Clinical evaluation}

A detailed medical and neurological history was taken as described before, including history of main vascular risk factors. ${ }^{16}$ Education was divided in two categories: low (0-6 years of formal education) and high ( $>6$ years of formal education). Smoking habits were scored at 
admission as non-smokers and smokers (current or former). History of myocardial infarction, cardiac failure, cardiac arrhythmia, atrial fibrillation, arterial hypertension, peripheral arterial disease and diabetes was investigated reviewing all available hospital charts, in addition to structured interview of the subject and a knowledgeable informant. History of hypertension was defined as systolic blood pressure $\geq 160 \mathrm{mmHg}$ and diastolic blood pressure $\geq 95 \mathrm{mmHg}$, according to cut off values used at the time of evaluation. Diabetes was defined as previously documented diagnosis, current use of insulin or oral hypoglycemic medication, or fasting blood glucose > $7.0 \mathrm{mmol} / \mathrm{L}$. Stroke severity was assessed using Modified Rankin score (1-5; 3-5 indicating severe stroke). ${ }^{19}$

Dementia was diagnosed using the Diagnostic and Statistical Manual of Mental Disorders, $3^{\text {rd }}$ edition. ${ }^{20}$ The clinical mental status examination by the neurologist assessed the following domains: attention; orientation; memory recall; executive functions including abstract thinking, judgment, and problem solving; aphasia; apraxia; agnosia; motor control; constructional and visuospatial abilities; and personal change as detailed previously. ${ }^{16}$ The clinical cognitive assessment included also the Folstein MMSE (maximum $=30$ ). ${ }^{21}$ In addition, social functioning was assessed using the Index of ADL (activities of daily living), ${ }^{22}$ the IADL scale (instrumental activities of daily living), ${ }^{23}$ the Functional Activity Questionnaire, ${ }^{24}$ the Blessed Functional Activity Scale ${ }^{25,26}$ and the Barthel Index. ${ }^{27}$

Assessment of prestroke cognitive decline was based on interviews with the patient and a knowledgeable informant. ${ }^{28}$ The interviews included structured questions on abnormality in the cognitive domains as well as assessment of social functions before the index stroke. The beginning of the symptoms and their duration was asked for, focusing especially on the period of one year before the index stroke. Based on all available history from the patient and 
knowledgeable informant, a board certified neurologist (TP) independently judged whether the patient had had prestroke cognitive decline or not. Patients with prestroke cognitive decline included also those with borderline and definite dementia.

\section{Survival data}

Longterm survival data and causes of death at 21 September 2006 were obtained from Statistics Finland. The mean (+-SD) follow up time was $7.5 \pm 4.0$ years with a range between 0.3 and 12.8 years. The death certificate data was reviewed by a forensic pathology specialist $(\mathrm{AO})$ and the causes of death were divided in cardiac, brain associated (differing between infarction, haemorrhage and dementia), infectious, traumatic, cancer or other causes of death.

\section{Data analysis and statistics}

SPSS/WIN (version 15.0, SPSS Inc) software was used. Pearson Chi-square test was used to test dichotomous variables and One-way ANOVA to continuous variables. The effect of dementia diagnosis (any poststroke dementia) was first analysed using Kaplan-Meier log rank analysis, as well as the effect of prestroke cognitive decline and previous stroke among the demented patients. The cumulative hazard function was also used and according to these analyses, the proportional hazards assumption was met for each parameter included in further models. In Cox-regression proportional hazards survival analysis, in the forced entry model (Model 1) the potential predictors were used as covariates (age, sex, years of education, in addition to poststroke dementia). Another model (Model 2) was constructed adding poor Rankin score as a covariate. A third model (Model 3) was constructed adding selected variables from the past medical history as covariates, selecting those variables which were indicated as significant predictors of poor longterm survival using Kaplan-Meier log rank analysis. Statistical significance was set at $p<0.05$. 


\section{Role of the funding source}

The funding source (declared under Acknowledgements) had no involvement in study design; in the collection, analysis and interpretation of data; in the writing of the report; nor in the decision to submit the paper for publication. The researchers have acted independent of funders. 


\section{Results}

\section{Demographics, previous medical history and stroke severity}

The basic demographics of the population $(n=451)$ are as follows: mean age $72.0 \pm 7.7$ years, female sex $49.0 \%(221 / 451)$, and low education $<6$ years $30.9 \%(137 / 443)$. The previous medical history of the population is following: current or former smoking $49.8 \%$ (224/450), myocardial infarction 19.1\% (86/451), cardiac failure 21.6\% (97/450), cardiac arrhythmia 25.3\% (114/451), atrial fibrillation 18.9\% (85/450), arterial hypertension $47.5 \%$ (214/451), peripheral arterial disease $11.8 \%$ (53/451), and diabetes $24.6 \%$ (111/451). $40.4 \%$ (163/403) of the patients had a severe stroke, indicated by Modified Rankin score between 35. $12.2 \%(55 / 451)$ of the patients had had a prestroke cognitive decline, and $20.0 \%(90 / 451)$ of the patients had had a previous stroke.

The univariate analysis of association between above mentioned variables and poststroke dementia are presented in Table 2. Patients with poststroke dementia were older $(p=0.002)$, had lower education $(p<0.001)$ and more severe stroke $(<0.001)$ than those without it. The proportion of patients with prestroke cognitive decline was higher than in patients without dementia (32.2 vs $5.4 \%, \mathrm{p}<0.001)$.

\section{Influence of poststroke dementia on survival}

In Kaplan-Meier log rank analysis, patients with dementia three months after stroke, i.e. with any poststroke dementia $(n=115,25.5 \%)$, had shorter median survival after stroke (5.1 years, Cl 4.1-6.0) than patients without dementia $(n=336,74.5 \%, 8.8$ years, Cl 7.8-9.9, $p<0.001)$. 
Among the demented stroke patients, those who had had a prestroke cognitive decline $(n=37,32.2 \%)$ had shorter median survival (3.8 years, $\mathrm{Cl} 2.2-5.4)$ than those without prestroke cognitive decline $(n=78,67.8 \%, 5.8$ years, $\mathrm{Cl} 4.8-6.9, \mathrm{p}<0.001)$. Further, among the demented patients there was no significant difference between survival of patients with their first ever stroke ( $n=90,78 \%, 5.4$ years, $\mathrm{Cl} 4.6-6.2)$ compared to those with at least one previous stroke $(n=25,22 \%, 4.5$ years, $\mathrm{Cl} 2.9-6.1, p=0.676)$.

To account for potential confounders and to estimate the predictive value of different factors, a multivariate Cox regression proportional hazards analysis was made in three steps, Model 1-3 (Table 3), as described above in Data analysis and statistics. In Model 3 we added selected variables from the past medical history indicated as significant predictors of poor longterm survival using Kaplan-Meier log rank analysis. These predictors were smoking, myocardial infarction, cardiac failure, cardiac arrhythmia and atrial fibrillation (all with $p<0.05)$, and also peripheral arterial disease with borderline significance $(p=0.058)$.

In Model 1 (Table 3), poststroke dementia and advanced age were independent predictors of poor longterm survival $(p<0.001)$. Adding stroke severity to the model (Model 2, Table 3), poststroke dementia remained associated with increased risk of death $(p=0.002)$, in addition to advanced age $(p=0.002)$ and poor Rankin score $(p<0.001)$. Finally in Model 3 (Table 3$)$, in addition to poststroke dementia (HR 1.53, $\mathrm{Cl} 1.15-2.04, \mathrm{p}=0.003)$, advanced age (HR 1.07, Cl 1.05-1.09, $\mathrm{p}<0.001)$, poor Rankin score (HR 1.91, Cl 1.47-2.48, $\mathrm{p}<0.001)$, smoking (HR 1.35, $\mathrm{Cl} 1.02-1.77, \mathrm{p}=0.035)$, cardiac failure (HR 1.61, $\mathrm{Cl} 1.18-2.19, \mathrm{p}=0.003)$ and atrial fibrillation (HR 1.89, Cl 1.05-3.42, p=0.035) remained as independent predictors of poor longterm survival. 
In univariate analysis of causes of death (Table 4), brain associated cause of death in general $(p=0.002)$ and especially brain infarction $(p=0.001)$ were associated with poststroke dementia. In Kaplan-Meier analysis with brain associated death as endpoint patients with poststroke dementia had shorter survival (6.8 years, $\mathrm{Cl} 4.6-8.9)$ compared to patients without dementia (11.1 years, $\mathrm{Cl} 10.2-11.9, \mathrm{p}<0.001)$. In multivariate Cox regression analysis using brain associated cause of death as endpoint and adding covariates in three steps (Table 5), poststroke dementia remained as independent predictor of poor survival $(p<0.001)$, in addition to advanced age $(p<0.001)$ and poor Rankin score $(p=0.001)$. Unexpected, in this population myocardial infarction in previous medical history seems to be associated with reduced risk for brain associated death (HR 0.49, $\mathrm{Cl} 0.26-0.94, \mathrm{p}=0.033)$. 


\section{Discussion}

The present large $(\mathrm{N}=451)$ well defined poststroke cohort with an up to 12 years follow-up showed that in patients with acute stroke, dementia is a significant predictor of poor longterm survival and death from brain associated causes. Prestroke cognitive decline but not previous stroke had an additional negative influence on survival.

This study is the longest follow-up confirming that poststroke dementia relates to poor survival. Previously Tatemichi et al. ${ }^{12}$ ( $\mathrm{N}=251$, follow-up 5 years) and Desmond et al. ${ }^{13}$ ( $N=453$, follow-up 10 years) came to same conclusion with comparable study designs and demographics. Similarly to our study in these two studies the result remained significant after controlling with major confounders. The study of Barba et al. ${ }^{15}(\mathrm{~N}=251$, follow-up 28.7 months) including also intracranial haemorrhages showed similar poor poststroke survival. The effect of poststroke dementia in the present study is somewhat weaker than that found in previous studies with longterm follow-up: HR 1.5 in the present study, compared with RR 3.1 in the study of Tatemichi and RR 2.4 in the study of Desmond, all after adjusting for major confounders.

Previous reports on prestroke dementia, its frequency and effects on survival ${ }^{14,15,29}$ can be compared with our findings with prestroke cognitive decline. Additional negative influence of prestroke dementia on the poststroke survival, in line with our finding, was reported in two of these studies, ${ }^{15,29}$ but not in one. ${ }^{14}$

First ever stroke is of interest because stroke alone is associated with shortened survival. ${ }^{2,3}$ However its influence has not been analysed separately in previous studies on poststroke 
survival. In the present study $21.7 \%$ of patients had had a previous stroke but previous stroke did not have an influence on survival ( 4.5 years with previous stroke vs. 5.4 years with first ever stroke).

In our study there was an association between poststroke dementia and brain associated cause of death, more specifically brain infarction. Previous studies have not found this association. ${ }^{13,14}$ Our result relies on the high validity of determination of causes of death in Finland. The cause of death has been verified by autopsy in $30 \%$ of all deaths in Finland in the past two decades (Statistics Finland, www.tilastokeskus.fi) which is rather high proportion compared to other European countries. In addition, the death certificates of all deceased, whether subjected to autopsy or not are reviewed by the district forensic physician. In the present study all death certificate data was in addition reviewed by a specialist in forensic medicine. The official cause of death has been demonstrated to be an accurate means for evaluating disease specific mortality in Finland. ${ }^{30}$

There was no specific association between poststroke dementia and dementia as a cause of death in our analysis. This probably has to do with the general restraint of using dementia as the primary cause of death otherwise than when there is clear evidence for primarily degenerative, progressive dementia, in particular Alzheimer disease. Fatal progression of vascular dementia is often associated with stroke recurrence, and in those cases the cause of death is brain infarction. Another observation is that in this population previous myocardial infarction seemed to be associated with reduced risk for brain associated death. A further analysis was done with multivariate Cox regression analysis using cardiac death as endpoint. The analysis showed tendency, although not significant $(p=0.095)$, that previous myocardial infarction is associated with increased risk for cardiac death. The result indicates that in 
patients with cardiac disease the cardiac mortality dominates irrespective of stroke, but further investigation is needed before we know if the result is generalisable.

A potential weakness of our study is the possibility of selection bias, as the cohort was formed three months after the index stroke. Attrition over three months may limit generalisation of the results. Therefore, we retrospectively obtained additional data on stroke related deaths in Helsinki University Hospital district during the collection of the cohort from an independent organisation (Statistics Finland, www.tilastokeskus.fi) . In this retrospective data, up to 64 percent of stroke related deaths occurred in women. While the proportions of both sexes in the present study were equal, this suggests that some women may have died before hospital assessment at three months. Due to exclusion of patients, the true survival rate may be underestimated. Another potential weakness relates to the definition of prestroke cognitive decline, which we based on detailed clinical history instead of a more reliable assessment with standardised IQCODE as did Henon et al. ${ }^{14}$ and Barba et al. ${ }^{15}$ No formal validation was carried out on our definition procedure, but the diagnosis relies on clinical competency and excessive efforts to find out relevant background information.

As noted above, cut off values for hypertension in our study are not consistent with current definitions. Previous studies have used cut off values comparable with our study. ${ }^{13,15}$ Hypertension has not been an independent predictor of survival in these studies either. Significance of hypertension according to current criteria remains to be examined in the future longterm follow ups of poststroke cohorts.

Strengths of our study are the well defined, large and consecutive cohort and the longterm follow up (12 years). The cohort has allowed analysis of the effect of prestroke cognitive 
decline and the effect of previous stroke on survival. The data on survival and causes of death is comprehensive with negligible amount of unresolved deaths. In addition, the diagnosis of dementia is similar with diagnosis in previous studies, allowing direct comparisons.

Since poststroke dementia significantly worsens the prognosis after stroke, especially in patients with prestroke cognitive decline, it is important to recognise patients with this condition to be able to offer them optimal comprehensive care. 


\section{Acknowledgements}

This study was supported by grants from the Clinical Research Institute, Helsinki University Central Hospital and the Medical Research Fund of Helsinki University Central Hospital. We thank Statistics Finland for their expert assistance in the data collection.

\section{Copyright}

The Corresponding Author has the right to grant on behalf of all authors and does grant on behalf of all authors, an exclusive license on a worldwide basis to the BMJ Publishing Group Ltd, and its Licensees to permit this article (if accepted) to be published in BMJ editions and any other BMJPGL products and to exploit all subsidiary rights, as set out in your licence (bmj.com/advice/copyright.shtml).

\section{Competing interest statement}

All authors declare that the answer to the questions on your competing interests form are all No and therefore have nothing to declare.

\section{Details of contributors}

The authors have contributed to the manuscript as follows: S Melkas designed the research, analysed and interpreted the data, performed statistical analysis and drafted the manuscript. NKJ Oksala designed the research, analysed and interpreted the data and drafted the manuscript. $\mathrm{H}$ Jokinen designed the research and made critical revision of the manuscript. $\mathrm{T}$ Pohjasvaara designed the research, acquired the data and drafted the manuscript. $\mathrm{R}$ Vataja 
designed the research, acquired the data and made critical revision of the manuscript. A Oksala analysed and interpreted the data. M Kaste conceived and designed the research, analysed and interpreted the data and made critical revision of the manuscript. PJ Karhunen conceived and designed the research and made critical revision of the manuscript. T Erkinjuntti conceived and designed the research, acquired the data, interpreted the data, drafted the manuscript, made critical revision of the manuscript and handled funding and supervision. The Corresponding Author S Melkas is the guarantor. 


\section{References}

1 Seshadri S, Beiser A, Kelly-Hayes M, Kase CS, Au R, Kannel WB, et al. The lifetime risk of stroke: estimates from the Framingham Study. Stroke 2006;37:345-50.

2 Eriksson SE, Olsson JE. Survival and recurrent strokes in patients with different subtypes of stroke: a fourteen-year follow-up study. Cerebrovasc Dis 2001;12:171-80.

3 Vernino S, Brown RD Jr, Sejvar JJ, Sicks JD, Petty GW, O'Fallon WM. Cause-specific mortality after first cerebral infarction: a population-based study. Stroke 2003;34:1828-32.

4 Xie J, Brayne C, Matthews FE, Medical Research Council Cognitive Function and Ageing Study, collaborators. Survival times in people with dementia: analysis from population based cohort study with 14 year follow-up. BMJ 2008;336:258-62.

5 Leys D, Henon H, Mackowiak-Cordoliani MA, Pasquier F. Poststroke dementia. Lancet Neurol 2005;4:752-9.

6 Moorhouse P, Rockwood K. Vascular cognitive impairment: current concepts and clinical developments. Lancet Neurol 2008;7:246-55.

7 Roman GC, Sachdev P, Royall DR, Bullock RA, Orgogozo JM, Lopez-Pousa S, et al. Vascular cognitive disorder: a new diagnostic category updating vascular cognitive impairment and vascular dementia. J Neurol Sci 2004;226:81-7.

8 Snowdon DA, Greiner LH, Mortimer JA, Riley KP, Greiner PA, Markesbery WR. Brain infarction and the clinical expression of Alzheimer disease. The Nun Study. JAMA $1997 ; 277: 813-7$.

9 Roman GC, Royall DR. A diagnostic dilemma: is "Alzheimer's dementia" Alzheimer's disease, vascular dementia, or both?[comment]. Lancet Neurol 2004;3:141. 
10 Hachinski V, ladecola C, Petersen RC, Breteler MM, Nyenhuis DL, Black SE, et al. National Institute of Neurological Disorders and Stroke-Canadian Stroke Network vascular cognitive impairment harmonization standards. Stroke 2006;37:2220-41.

11 Tyas SL, Snowdon DA, Desrosiers MF, Riley KP, Markesbery WR. Healthy ageing in the Nun Study: definition and neuropathologic correlates. Age Ageing 2007;36:650-5.

12 Tatemichi TK, Paik M, Bagiella E, Desmond DW, Pirro M, Hanzawa LK. Dementia after stroke is a predictor of long-term survival. Stroke 1994;25:1915-9.

13 Desmond DW, Moroney JT, Sano M, Stern Y. Mortality in patients with dementia after ischemic stroke. Neurology 2002;59:537-43.

14 Henon H, Durieu I, Lebert F, Pasquier F, Leys D. Influence of prestroke dementia on early and delayed mortality in stroke patients. J Neurol 2003;250:10-6.

15 Barba R, Morin MD, Cemillan C, Delgado C, Domingo J, Del Ser T. Previous and incident dementia as risk factors for mortality in stroke patients. Stroke 2002;33:1993-8.

16 Pohjasvaara T, Erkinjuntti T, Vataja R, Kaste M. Comparison of stroke features and disability in daily life in patients with ischemic stroke aged 55 to 70 and 71 to 85 years. Stroke 1997;28:729-35.

17 Oksala NK, Heikkinen M, Mikkelsson J, Pohjasvaara T, Kaste M, Erkinjuntti T, Karhunen PJ. Smoking and the platelet fibrinogen receptor glycoprotein IIb/IIIA PIA1/A2 polymorphism interact in the risk of lacunar stroke and midterm survival. Stroke 2007;38:50-

5.

18 Mantyla R, Aronen HJ, Salonen O, Pohjasvaara T, Korpelainen M, Peltonen T, Standertskjold-Nordenstam CG, Kaste M, Erkinjuntti T. Magnetic resonance imaging white matter hyperintensities and mechanism of ischemic stroke. Stroke 1999;30:2053-8. 
19 van Swieten JC, Koudstaal PJ, Visser MC, Schouten HJ, van Gijn J. Interobserver agreement for the assessment of handicap in stroke patients. Stroke 1988;19:604-7.

20 American Psychiatric Association Committee on Nomenclature and Statistics:

Diagnostic and Statistical Manual of Mental Disorders (DSM-III). Washington D.C.: American Psychiatric Association; 1980.

21 Folstein MF, Folstein SE, McHugh PR. "Mini-mental state". A practical method for grading the cognitive state of patients for the clinician. J Psychiatr Res 1975;12:189-98.

22 Katz S, Downs TD, Cash HR, Grotz RC. Progress in development of the index of ADL. Gerontologist 1970;10:20-30.

23 Lawton MP, Brody EM. Assessment of older people: self-maintaining and instrumental activities of daily living. Gerontologist 1969;9:179-86.

24 Pfeffer RI, Kurosaki TT, Harrah $\mathrm{CH}$,Jr, Chance JM, Filos S. Measurement of functional activities in older adults in the community. J Gerontol 1982;37:323-9.

25 Blessed G, Tomlinson BE, Roth M. The association between quantitative measures of dementia and of senile change in the cerebral grey matter of elderly subjects. Br J Psychiatry 1968;114:797-811.

26 Erkinjuntti T, Hokkanen L, Sulkava R, Palo J. The Blessed Dementia Scale as a screening test for dementia. Int J Geriatr Psychiatry 1988;51:267-73.

27. Mahoney FI, Barthel DW. Functional evaluation: The Barthel Index. A simple index of independence useful in scoring improvement in the rehabilitation of the chronically ill. $M d$ State Med J 1965;14:61-5. 
28 Pohjasvaara T, Mantyla R, Aronen HJ, Leskela M, Salonen O, Kaste M, Erkinjuntti T. Clinical and radiological determinants of prestroke cognitive decline in a stroke cohort. $J$ Neurol Neurosurg Psychiatry 1999; Dec;67(6):742-8.

29 Appelros $\mathrm{P}$, Viitanen $\mathrm{M}$. What causes increased stroke mortality in patients with prestroke dementia?. Cerebrovasc Dis 2005;19(5):323-7.

30 Makinen T, Karhunen P, Aro J, Lahtela J, Maattanen L, Auvinen A. Assessment of causes of death in a prostate cancer screening trial. Int $J$ Cancer 2008;122:413-7. 


\section{Figure legends}

Figure 1. The effect of poststroke dementia on overall poststroke survival (endpoint all cause death) in Stroke Aging Memory cohort. Kaplan-Meier log rank analysis.

Figure 2. The effect of prestroke cognitive decline on survival of patients with poststroke dementia (endpoint all cause death) in Stroke Aging Memory cohort. Kaplan-Meier log rank analysis.

Figure 3. The effect of previous stroke on survival of patients with poststroke dementia (endpoint all cause death) in Stroke Aging Memory cohort. Kaplan-Meier log rank analysis. 
Table 1. Patient flow in the Helsinki Stroke Aging Memory Study.

\begin{tabular}{|c|c|}
\hline \multirow[t]{3}{*}{ Consecutive patients with suspected stroke $\mathrm{N}=1622$} & Not fulfilling the current criteria for stroke $n=175$ \\
\hline & Intracerebral haemorrhage $n=229$ \\
\hline & Subarachnoidal haemorrhage $n=69$ \\
\hline \multirow[t]{3}{*}{ Patients with ischaemic stroke $n=1149$} & Age under 55 or over 85 years $n=346$ \\
\hline & Not living in the city of Helsinki $n=158$ \\
\hline & Not speaking Finnish language $n=3$ \\
\hline \multirow[t]{3}{*}{ Fulfilling inclusion criteria, invited to 3 month follow-up $n=642$} & Death before the 3 month follow-up $n=71$ \\
\hline & Refused $n=82$ \\
\hline & Lost $n=3$ \\
\hline \multirow[t]{4}{*}{ Clinical evaluation at 3 months poststroke $n=486$} & Severe aphasia $\mathrm{n}=32$ \\
\hline & Severe hearing impairment $n=1$ \\
\hline & Reduced level of conscience $n=1$ \\
\hline & Refused during examination $n=1$ \\
\hline
\end{tabular}


Table 2. The association of poststroke dementia with demographic parameters, previous medical history and stroke severity.

\begin{tabular}{|c|c|c|c|c|c|c|c|}
\hline \multirow[b]{2}{*}{ Variable } & \multicolumn{3}{|c|}{ No dementia } & \multicolumn{4}{|c|}{ Any poststroke dementia } \\
\hline & Valid $n$ & Mean/n & $(\mathrm{SD} / \%)$ & Valid $n$ & Mean/n & $(\mathrm{SD} / \%)$ & $p$ value \\
\hline Mean age & 336 & 70.4 & $(7.6)$ & 115 & 72.9 & $(7.6)$ & 0.002 \\
\hline Female sex & 336 & 162 & $(48.2)$ & 115 & 59 & $(51.3)$ & 0.567 \\
\hline Low education (<6yr) & 331 & 83 & $(25.1)$ & 112 & 54 & $(48.2)$ & $<0.001$ \\
\hline Smoking (current/former) & 335 & 164 & $(49.0)$ & 115 & 60 & $(52.2)$ & 0.551 \\
\hline Myocardial infarction & 336 & 64 & $(19.0)$ & 115 & 22 & $(19.1)$ & 0.984 \\
\hline Cardiac failure & 335 & 69 & $(20.6)$ & 115 & 28 & $(24.3)$ & 0.399 \\
\hline Cardiac arrhythmia & 336 & 85 & $(25.3)$ & 115 & 29 & $(25.2)$ & 0.986 \\
\hline Atrial fibrillation & 335 & 59 & $(17.6)$ & 115 & 26 & $(22.6)$ & 0.238 \\
\hline Arterial hypertension & 336 & 161 & $(47.9)$ & 115 & 53 & $(46.1)$ & 0.734 \\
\hline Peripheral arterial disease & 336 & 39 & $(11.6)$ & 115 & 14 & $(12.2)$ & 0.871 \\
\hline Diabetes & 336 & 78 & $(23.2)$ & 115 & 33 & $(28.7)$ & 0.239 \\
\hline Poor Rankin score & 305 & 100 & $(32.8)$ & 98 & 63 & $(64.3)$ & $<0.001$ \\
\hline Prestroke cognitive decline & 336 & 18 & $(5.4)$ & 115 & 37 & $(32.2)$ & $<0.001$ \\
\hline Previous stroke & 336 & 65 & (19.3) & 115 & 25 & $(21.7)$ & 0.579 \\
\hline
\end{tabular}

Dichotomous variables: Pearson Chi-square test

Continuous variables: One-way ANOVA 
Table 3. Cox regression analysis on the association of multiple risk factors and poststroke dementia with poor longterm survival (all cause death endpoint) among patients with ischaemic stroke (Stroke Aging Memory cohort).

\begin{tabular}{|c|c|c|c|c|c|c|c|c|c|}
\hline \multirow[b]{2}{*}{ Variable } & \multicolumn{3}{|c|}{ Model 1, forced entry } & \multicolumn{3}{|c|}{ Model 2, forced entry } & \multicolumn{3}{|c|}{ Model 3, forced entry } \\
\hline & $\mathrm{HR}$ & $95 \% \mathrm{Cl}$ & $p$ value & $\mathrm{HR}$ & $95 \% \mathrm{Cl}$ & $\mathrm{p}$ value & $\mathrm{HR}$ & $95 \% \mathrm{Cl}$ & $p$ value \\
\hline Age & 1.08 & $1.06-1.09$ & $<0.001$ & 1.07 & $1.12-2.06$ & 0.002 & 1.07 & $1.05-1.09$ & $<0.001$ \\
\hline Female sex & 0.77 & $0.68-0.97$ & 0.028 & 0.80 & $0.62-1.03$ & 0.089 & 0.88 & $0.66-1.16$ & 0.352 \\
\hline Low education $<6$ years & 1.07 & $0.83-1.37$ & 0.609 & 0.95 & $0.72-1.25$ & 0.707 & 0.92 & $0.69-1.21$ & 0.544 \\
\hline Poor Rankin score & - & & & 1.85 & $1.43-2.39$ & $<0.001$ & 1.91 & $1.47-2.48$ & $<0.001$ \\
\hline Smoking (current/former) & - & & & - & & & 1.35 & $1.02-1.77$ & 0.035 \\
\hline Myocardial infarction & - & & & - & & & 1.08 & $0.78-1.49$ & 0.661 \\
\hline Cardiac failure & - & & & - & & & 1.61 & $1.18-2.19$ & 0.003 \\
\hline Cardiac arrhythmia & - & & & - & & & 0.73 & $0.42-1.25$ & 0.246 \\
\hline Atrial fibrillation & - & & & - & & & 1.89 & $1.05-3.42$ & 0.035 \\
\hline Peripheral arterial disease & - & & & - & & & 1.09 & $0.75-1.58$ & 0.663 \\
\hline Poststroke dementia & 1.71 & $1.33-2.20$ & $<0.001$ & 1.56 & $1.18-2.06$ & 0.002 & 1.53 & $1.15-2.04$ & 0.003 \\
\hline
\end{tabular}


Table 4. The association of poststroke dementia with causes of death in Stroke Aging Memory cohort.

\begin{tabular}{lllllll} 
& \multicolumn{3}{c}{ No dementia } & \multicolumn{2}{c}{ Any poststroke } \\
Variable & Valid $\mathrm{n}$ & $\mathrm{n}$ & $\%$ & $\mathrm{n}$ & $\%$ & $\mathrm{p}$ value \\
Cardiac & 91 & 68 & $(31.1)$ & 23 & $(23.0)$ & 0.140 \\
Brain & 108 & 62 & $(28.3)$ & 46 & $(46.0)$ & 0.002 \\
$\quad$ Infarction & 87 & 47 & $(21.5)$ & 40 & $(40.0)$ & 0.001 \\
Haemorrhage & 11 & 8 & $(3.7)$ & 3 & $(3.0)$ & 0.767 \\
$\quad$ Dementia & 10 & 7 & $(3.2)$ & 3 & $(3.0)$ & 0.926 \\
Infectious & 15 & 9 & $(4.1)$ & 6 & $(6.0)$ & 0.459 \\
Traumatic & 11 & 8 & $(3.7)$ & 3 & $(3.0)$ & 0.767 \\
Cancer & 45 & 35 & $(16.0)$ & 10 & $(10.0)$ & 0.154 \\
Other & 40 & 28 & $(12.8)$ & 12 & $(12.0)$ & 0.844
\end{tabular}

Pearson Chi-square test

*The cause of death unknown for 9 subjects, all with no dementia. 
Table 5. Cox regression analysis on the association of multiple risk factors and poststroke dementia with poor longterm survival (brain associated death endpoint) among patients with ischaemic stroke (Stroke Aging Memory cohort).

\begin{tabular}{|c|c|c|c|c|c|c|c|c|c|}
\hline \multirow[b]{2}{*}{ Variable } & \multicolumn{3}{|c|}{ Model 1 , forced entry } & \multicolumn{3}{|c|}{ Model 2, forced entry } & \multicolumn{3}{|c|}{ Model 3, forced entry } \\
\hline & $\mathrm{HR}$ & $95 \% \mathrm{Cl}$ & $p$ value & $\mathrm{HR}$ & $95 \% \mathrm{Cl}$ & $p$ value & $\mathrm{HR}$ & $95 \% \mathrm{Cl}$ & $p$ value \\
\hline Age & 1.07 & $1.04-1.11$ & $<0.001$ & 1.08 & $1.04-1.11$ & $<0.001$ & 1.07 & $1.04-1.11$ & $<0.001$ \\
\hline Female sex & 1.10 & $0.74-1.64$ & 0.641 & 1.00 & $0.65-1.55$ & 0.998 & 0.85 & $0.52-1.39$ & 0.513 \\
\hline Low education $<6$ years & 0.93 & $0.60-1.42$ & 0.721 & 0.76 & $0.47-1.23$ & 0.266 & 0.77 & $0.47-1.26$ & 0.295 \\
\hline Poor ranking score & - & & & 2.17 & $1.36-3.45$ & 0.001 & 2.15 & $1.34-3.46$ & 0.001 \\
\hline Smoking (current/former) & - & & & - & & & 0.75 & $0.46-1.25$ & 0.267 \\
\hline Myocardial infarction & - & & & - & & & 0.49 & $0.26-0.94$ & 0.033 \\
\hline Cardiac failure & - & & & - & & & 1.03 & $0.58-1.83$ & 0.914 \\
\hline Cardiac arrhythmia & - & & & - & & & 1.05 & $0.42-2.58$ & 0.925 \\
\hline Atrial fibrillation & - & & & - & & & 1.43 & $0.53-3.89$ & 0.482 \\
\hline Peripheral arterial disease & - & & & - & & & 1.31 & $0.72-2.41$ & 0.378 \\
\hline Poststroke dementia & 2.22 & $1.48-3.35$ & $<0.001$ & 2.36 & $1.49-3.73$ & $<0.001$ & 2.33 & $1.46-3.73$ & $<0.001$ \\
\hline
\end{tabular}


Figure 1

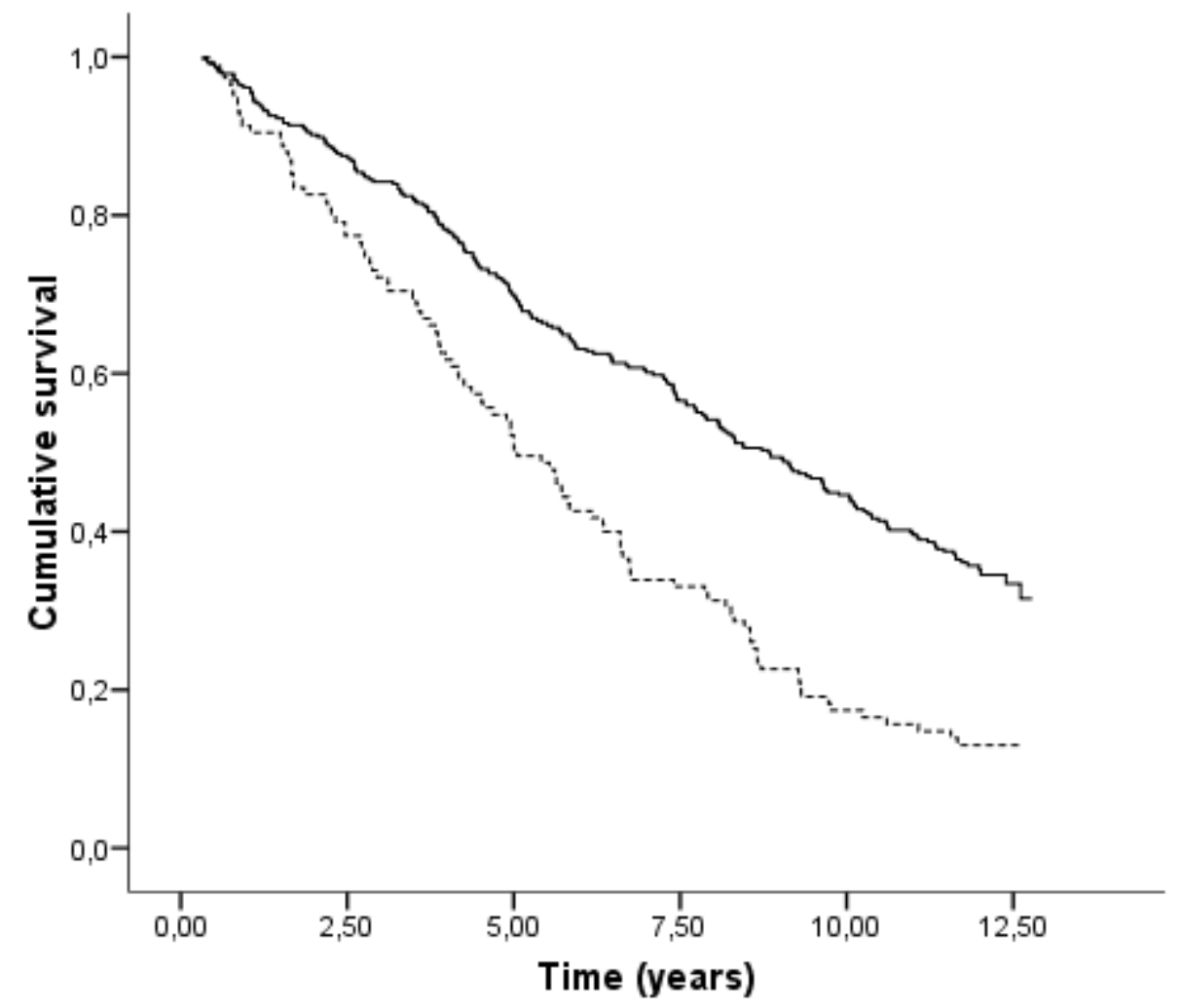

No dementia 8.8 years

...--- Any poststroke dementia 5.1 years $p<0.001$

$\begin{array}{lrrrrrrl}\text { Patients at risk } & 336 & 294 & 235 & 190 & 150 & 23 & \text { No dementia } \\ & 115 & 89 & 59 & 38 & 20 & 3 & \text { Any poststroke dementia }\end{array}$




\section{Figure 2}

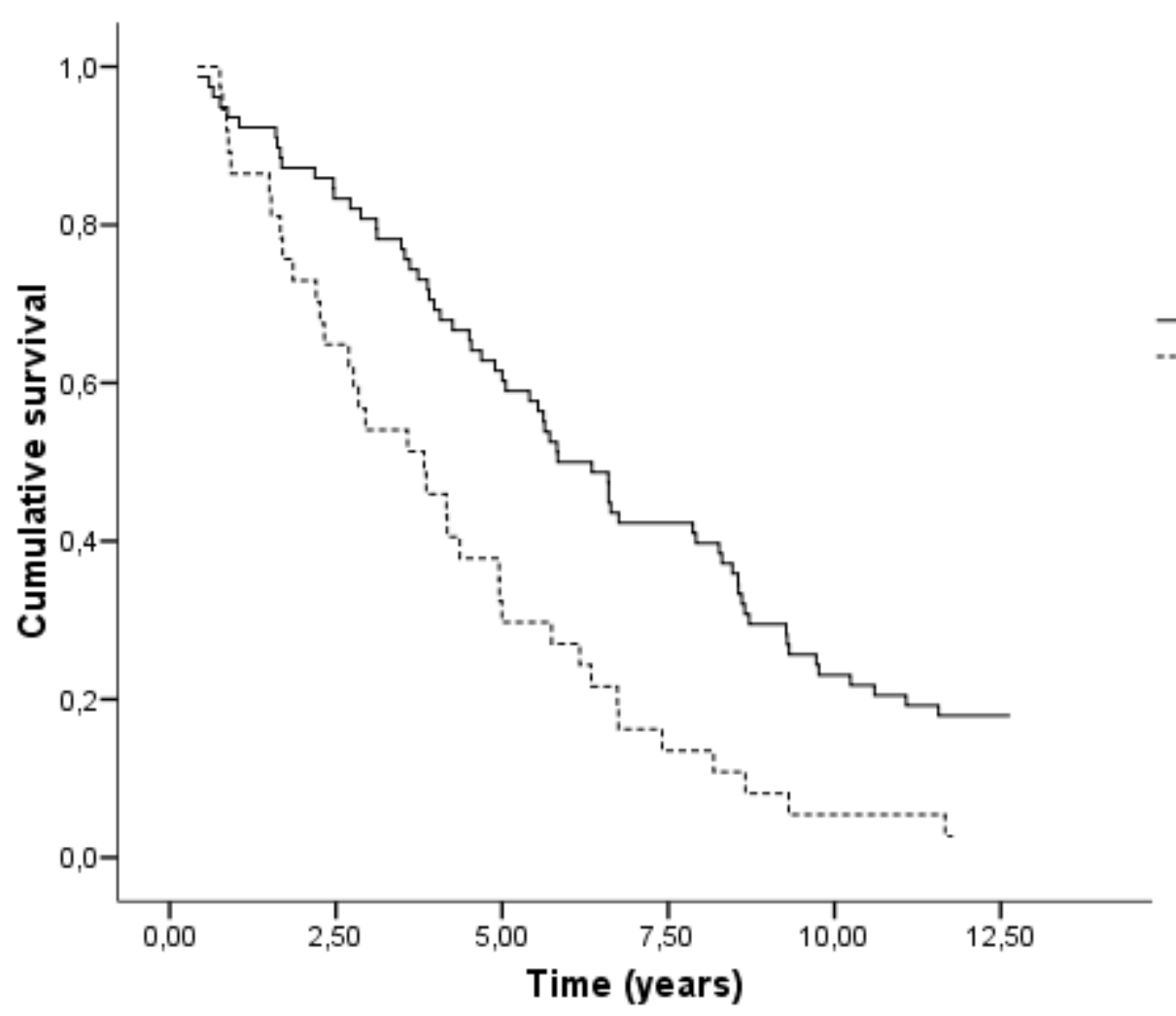

$\neg$ Without prestroke cognitive decline 5.8 years

With prestroke cognitive decline 3.8 years $\mathrm{p}<0.001$

$5 \quad 2$

With prestroke cognitive decline 
Figure 3

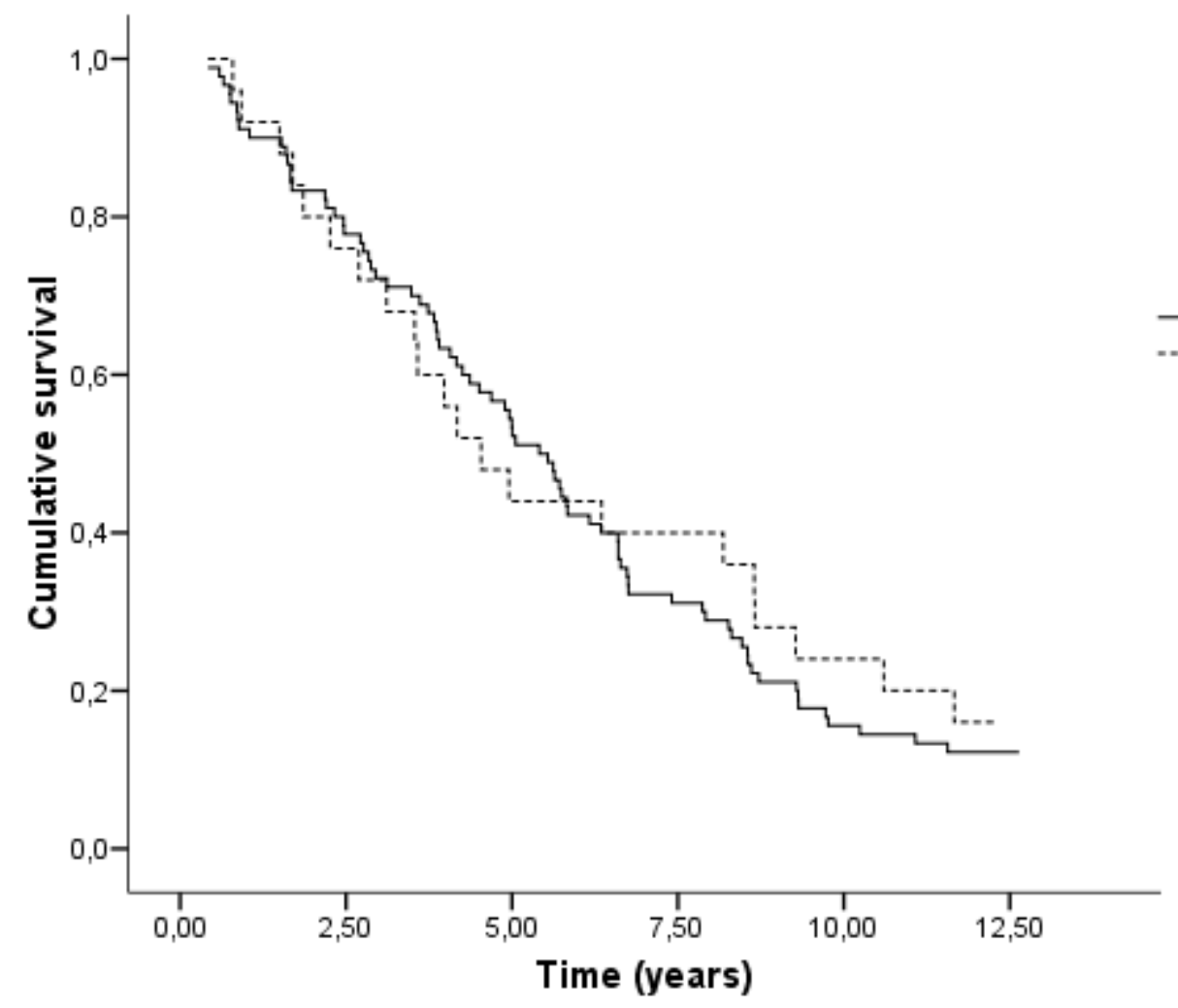

First ever stroke 5.4 years

At least one previous stroke 4.5 years $\mathrm{p}=0.676$

Patients at risk

$\begin{array}{lll}90 & 70 & 48 \\ 25 & 19 & 11\end{array}$

28

$14 \quad 3$

3
0

First ever stroke

At least one previous stroke 